\title{
Linking molecular deadwood-inhabiting fungal diversity and community dynamics to ecosystem functions and processes in Central European forests
}

\author{
Björn Hoppe ${ }^{1,2}$ - Witoon Purahong ${ }^{1,3} \cdot$ Tesfaye Wubet ${ }^{1,4} \cdot$ Tiemo Kahl $^{2}$ • \\ Jürgen Bauhus $^{2} \cdot$ Tobias Arnstadt $^{5} \cdot$ Martin Hofrichter $^{5}$ - François Buscot $^{1,4}$. \\ Dirk Krüger ${ }^{1}$
}

Received: 5 March 2015 / Accepted: 22 July 2015 / Published online: 11 August 2015

(C) The Author(s) 2015. This article is published with open access at Springerlink.com

\begin{abstract}
Fungi play vital roles in the decomposition of deadwood due to their secretion of various enzymes that break down plant cell-wall complexes. The compositions of woodinhabiting fungal (WIF) communities change over the course of the decomposition process as the remaining mass of wood decreases and both abiotic and biotic conditions of the wood significantly change. It is currently not resolved which substrate-related factors govern these changes in WIF communities and whether such changes influence the deadwood decomposition rate. Here we report a study on fungal richness and community structure in deadwood of Norway spruce and European beech in temperate forest ecosystems using 454
\end{abstract}

Björn Hoppe, Witoon Purahong and Tesfaye Wubet contributed equally to this work.

Electronic supplementary material The online version of this article (doi:10.1007/s13225-015-0341-x) contains supplementary material, which is available to authorized users.

Björn Hoppe

bjoern.hoppe@ufz.de

1 Department of Soil Ecology, UFZ-Helmholtz Centre for Environmental Research, Theodor-Lieser-Str. 4, D-06120 Halle (Saale), Germany

2 Faculty of Environment and Natural Resources, Chair of Silviculture, University of Freiburg, Tennenbacherstr. 4, D-79085 Freiburg i. Brsg., Germany

3 Technical University of Munich, Chair for Soil Science, Ingolstädter Landstr. 1, D-85758 Oberschleissheim, Germany

4 German Centre for Integrative Biodiversity Research (iDiv), Halle-Jena-Leipzig, Deutscher Platz 5e, D-04103 Leipzig, Germany

5 Department of Bio- and Environmental Sciences, Technical University of Dresden, International Institute (IHI) Zittau, Markt 23, D-02763 Zittau, Germany pyrosequencing. Our aims were to disentangle the factors that correspond to WIF community composition and to investigate the links between fungal richness, taxonomically-resolved fungal identity, and microbial-mediated ecosystem functions and processes by analyzing physico-chemical wood properties, lignin-modifying enzyme activities and wood decomposition rates. Unlike fungal richness, we found significant differences in community structure between deadwood of different tree species. The composition of WIF communities was related to the physico-chemical properties of the deadwood substrates. Decomposition rates and the activities of ligninmodifying enzymes were controlled by the succession of the fungal communities and competition scenarios rather than fungal OTU richness. Our results provide further insights into links between fungal community structure and microbialmediated ecosystem functions and processes.

Keywords Ecosystem processes $\cdot$ Enzyme activity $\cdot$ Wood decay · Physico-chemical wood properties · Ascomycetes . Basidiomycetes $\cdot$ Pyrosequencing

\section{Introduction}

Deadwood is one of the most important organic carbon pools in forest ecosystems (Floudas et al. 2012). Due to its lignin content of $15-40 \%$, deadwood is rather difficult to decompose and is therefore an important temporal store of carbon and macronutrients (Kopra and Fyles 2005; Krankina et al. 1999; Sarkanen and Ludwig 1971). Microorganisms, mainly fungi, play crucial roles in forest ecosystems. Their diversity and enzymatic activities constitute the basis for the food-webs in wood and litter (Pollierer et al. 2012; Stokland et al. 2012). Filamentous fungi of the phyla Basidiomycota and (to a lesser 
extent) Ascomycota are particularly important in lignin mineralization. White-rot fungi secrete a set of extracellular oxidative enzymes such as laccase (Lac, EC 1.10.3.2), manganese peroxidase (MnP, EC 1.11.1.13) and/or manganese independent peroxidases (MiP) to oxidize the recalcitrant lignin polymer (Hofrichter et al. 2010). In contrast, brown-rot fungi do not secrete these enzymes. Instead, they oxidize lignin via a mechanism relying on hydroxyl radicals, which are generated via the Fenton reaction (Hatakka and Hammel 2011; Jellison et al. 1997; Martinez et al. 2005).

The decomposition processes driven by decomposer organisms are complex and influenced by the host tree species and environmental factors (Boddy 2001). Different fungal species have different capacities for wood decomposition (Valmaseda et al. 1990) and have further been reported to be dependently related to different tree species (Rajala et al. 2010). Moreover, the identity of the host tree determines several key abiotic substrate factors that influence the interactions between the resident microbiota along with their growth, reproduction, and metabolism (Gadd 2010; Kögel-Knabner 2002). These factors include the chemical properties and cell structure of the wood (Schwarze et al. 2000) as well as its $\mathrm{pH}$ and water content.

The existing ecological data on wood-inhabiting fungi (WIF) in Central European forests, including information on their diversity patterns, resource use and the determinants of their community structure, was primarily obtained via sporocarp surveys (Blaser et al. 2013; Heilmann-Clausen and Christensen 2003; Müller et al. 2007), which only record the composition of a portion of the actively reproducing fungal community at a specific point in time. However, the macroscopically observable fungal flora may not be fully representative of the fungal community that is present, especially if sampling is only conducted once or over a short period of time (Halme and Kotiaho 2012). In contrast, high-throughput sequencing allows for detailed analysis of community composition and may thus uncover a hitherto concealed fungal diversity residing in deadwood. This approach has been used to study WIF communities within and among Norway spruce (Picea abies) logs (Kubartova et al. 2012) and to test the link between fungal life history and population dynamics (Ovaskainen et al. 2013). As expected, these studies revealed much higher fungal species richness than previously published sporocarp surveys and suggested that highly abundant fruiting species may be only weakly representing the fungal community as a whole.

All of the European high-throughput sequencing based studies on WIF conducted to date focused on deadwood of either gymnosperm tree species, Picea abies, in a single biome, the boreal forest zone of Northern Europe (Kubartova et al. 2012; Ovaskainen et al. 2010, 2013) or two angiosperm tree species, Fagus sylvatica and Quercus robur in temperate forests (Hiscox et al. 2015; van der Wal et al. 2015).
Therefore, our information on community dynamics of WIF in deadwood of different tree species in the same forest ecosystem at different locations is still limited. Our investigation is also the first to explore the fungal diversity in deadwood of European beech under natural condition using contemporary massively parallel sequencing techniques. In line with recent findings of Ottosson et al. (2015), we also expected deadwood of European beech and Norway spruce species to harbor a significant proportion of rare taxa, ones that are not presented through high sequence abundances. Links between fungal richness, taxonomically resolved community composition, and ecosystem processes are rarely studied, especially under natural conditions (van der Wal et al. 2015).

In this study, we aimed to: (i) using 454 pyrosequencing to compare the diversity and community structure of WIF in deadwood of two silviculturally important tree species found in Central European temperate forests - the coniferous Picea abies and the deciduous Fagus sylvatica, (ii) disentangling the ecological and environmental factors that correlate with WIF community structure, and (iii) using the resulting data to link WIF richness and taxonomically-resolved identity to microbial-mediated ecosystem functions (lignin-modifying enzyme activities) and processes (wood decomposition rates). We hypothesized that the different wood physicochemical properties of the two tree species could lead to significant differences in fungal richness and community structure. The different physico-chemical parameters are linked to wood decay and how fungal decomposition of the wood alters their own environment. Specifically during wood decomposition (decreasing of wood density), $\mathrm{C} / \mathrm{N}$ ratio decreases as a result of $\mathrm{N}$ accumulation and at the same time, lignin and wood moisture increase. The degrees how wood physico-chemical properties as well as macro-and micro-nutrient changes may depend greatly on the initial properties of each tree species.

In this study the lignin-modifying enzyme activities (indicator for lignin decomposition) and wood decomposition rates (indicator for decomposition process) were used as a proxy for microbial-mediated ecosystem functions and processes, respectively. Some studies have shown that species richness was found to positively link or promote stability of the ecosystem function in soil systems, however this is still unclear in the case of deadwood-inhabiting fungi under field conditions (van der Heijden et al. 1998; Coleman and Whitman 2005; Proulx et al. 2010; Eisenhauer et al. 2012). In a recent study, it was shown (under an artificial set-up) that fungal diversity was associated with wood decomposition rates in the intermediate decay stages, as determined by respiration rates (Valentin et al. 2014). Since the loss of microbial biodiversity could alter ecosystem functioning and stability, we expected positive correlations between fungal richness and the activities of ligninmodifying enzymes and wood decomposition rates. 


\section{Material and methods}

\section{Experimental design, deadwood selection and sampling}

The study was conducted on forest plots of the German Biodiversity Exploratories (Fischer et al. 2010) located in the UNESCO Biosphere Reserve "Schwäbische Alb" in southwestern Germany. The plot selection criteria were based on forest history and management regimes, dominant tree species and deadwood status (Fischer et al. 2010; Hessenmöller et al. 2011 and Luyssaert et al. 2011). All selected forest plots had, apparently, been subjected neither to clear-cutting procedures nor to a period of agricultural use in the past (Luyssaert et al. 2011). A minimum distance between the outer edges of each plot is $200 \mathrm{~m}$ and located at least $100 \mathrm{~m}$ from the nearest forest edge. Our survey took place on deadwood logs in 9 intensively investigated 1 ha plots, with three plots representing the following three forest management types, respectively: (i) natural beech forests (unmanaged for 100 years, natural regeneration, uneven-aged forest structure, with mature trees $>100$ years), (Hessenmöller et al. 2011), (ii) age-class managed beech forests dominated by Fagus sylvatica (natural regeneration, even-aged forest structure, 50-100 years) and (iii) age-class managed spruce forests dominated by Picea abies (planted forest, even-aged forest structure, $80-100$ years) (Tables S1, S2). In April 2009, a set of 48 logs, equally representing the two tree species ( $P$. abies and $F$. sylvatica) located on the forest floor were randomly selected and their properties (length, diameter, tree species, etc.) were characterized. Our selection assured that Fagus logs were present in Picea-dominated plots and vice versa. In June 2009, 3-7 wood samples were taken from each log (according to its size) using a cordless Makita BDF451 drill (Makita, Anja, Japan) equipped with a $2 \times 42 \mathrm{~cm}$ wood auger as described in Hoppe et al. $(2014,2015)$ and Purahong et al. $(2014 a, b)$. Sporocarp data were available (Hoppe et al. 2014) and used as corroborative evidence for the presence of particular fungi that were detected as OTUs in the sequencing analysis.

\section{Wood physico-chemical properties and lignin-modifying enzyme assays}

The concentrations of $\mathrm{C}$ and $\mathrm{N}$ in wood samples were determined by total combustion using a Truspec elemental analyzer (Leco, St. Joseph, MI, USA). Klason lignin content was determined gravimetrically as the dry mass of solids remaining after sequential hydrolysis with sulfuric acid $(72 \% w / w)$; in a second step, acid soluble lignin was measured by UVphotometry in $4 \% \mathrm{H}_{2} \mathrm{SO}_{4}$ (Effland 1977; Liers et al. 2011). Total lignin was obtained by summing acid insoluble Klason lignin and acid soluble lignin (Raiskila et al. 2007). The wood samples' $\mathrm{pH}$ values and contents of nutrient ions and ligninmodifying enzymes were measured in aqueous extracts. The extractions were performed using $10 \mathrm{ml}$ distilled water per $1 \mathrm{~g}$ dry mass of wood for $120 \mathrm{~min}$ on a rotary shaker (120 rpm). Macronutrients $(\mathrm{Mg}, \mathrm{K}, \mathrm{Ca}, \mathrm{Fe})$ and micronutrients $(\mathrm{Cu}, \mathrm{Mn}$, $\mathrm{Zn}, \mathrm{Ni}$ ) were determined using inductively coupled plasma (ICP) optical emission spectrometry (ICP-OES) and mass spectrometry (ICP-MS), according to the instrument manufacturers' specifications. Three oxidative extracellular oxidoreductases important for lignin degradation (laccase - Lac, manganese peroxidase - MnP, manganese-independent peroxidases - MiP) (Hatakka and Hammel 2011) were measured as described by Hahn et al. (2013). Nutrient ion and ligninmodifying enzyme analyses were conducted in triplicate and in duplicate, respectively, on the same subsamples.

Deadwood logs were assigned to four decay classes based on remaining mass (\%) data by k-means cluster analysis as described in Hoppe et al. (2014) and Kahl et al. (2012). Decay rates were calculated based on a single exponential model (Harmon et al. 1986) using information on mass loss (density and volume loss) and time since death obtained by dendrochronological dating of the deadwood (further details are provided in suppl. information).

\section{DNA isolation, PCR and pyrosequencing}

Total community DNA was isolated from $1 \mathrm{~g}$ of each homogenized wood sample using a modified CTAB-protocol (Doyle and Doyle 1987) as described in Hoppe et al. (2014). All DNA extracts from the wood samples of each log were pooled into a composite extract prior to PCR. Fungal ITS rDNA amplicon libraries were produced as described in Wubet et al. (2012). Briefly we used fusion primers designed with pyrosequencing primer B, a barcode and the fungal specific primer ITS1-F (Gardes and Bruns 1993) as a forward primer and pyrosequencing primer A and the universal eukaryotic primer ITS4 (White et al. 1990) as a reverse primer to amplify the fungal nuclear ribosomal internal transcribed spacer (nrITS) rDNA. We used a set of $10 \mathrm{nt}$ MID-barcodes provided by Roche Applied Science (Mannheim, Germany). Each composite DNA extract for the amplicon libraries was amplified separately by PCR in triplicate $50 \mu \mathrm{l}$ reaction mixtures containing $25 \mu \mathrm{l}$ 2x GoTaq Green Mastermix (Promega, Madison, WI, USA), $25 \mu \mathrm{M}$ of each primer and approximately $20 \mathrm{ng}$ template DNA. Amplification was performed using a touchdown PCR program with denaturation at $95^{\circ} \mathrm{C}$ for 5 min followed by 10 cycles of denaturation at $94^{\circ} \mathrm{C}$ for $30 \mathrm{~s}$, annealing at 60 $50{ }^{\circ} \mathrm{C}$ for $45 \mathrm{~s}\left(-1{ }^{\circ} \mathrm{C}\right.$ per cycle), and extension at $72{ }^{\circ} \mathrm{C}$ for $2 \mathrm{~min}$, followed by 30 cycles of $94{ }^{\circ} \mathrm{C}$ for $30 \mathrm{~s}, 50{ }^{\circ} \mathrm{C}$ for $45 \mathrm{~s}$ and $72{ }^{\circ} \mathrm{C}$ for $2 \mathrm{~min}$, with a final $10 \mathrm{~min}$ extension step at $72{ }^{\circ} \mathrm{C}$ (Lentendu et al. 2014). The PCR products were separated on a $1.5 \%$ agarose gel and equimolar volumes of the amplified products of the expected size from the three positive replicate amplicons per sample were homogenized. The pooled products were gel purified using a Qiagen Gel 
Extraction Kit (Qiagen, Hilden, Germany). The purified DNA was quantified using a fluorescence spectrophotometer (Cary Eclipse, Agilent Technologies, Waldbronn, Germany). An equimolar mixture of each library was subjected to unidirectional pyrosequencing from the ITS4 end of the amplicons, using a 454 Titanium amplicon sequencing kit and a Genome Sequencer FLX 454 System (454 Life Sciences/ Roche Applied Science) at the UFZ Department of Soil Ecology.

\section{Bioinformatic analysis}

We performed multiple levels of sequence quality filtering. The fungal ITS sequences were extracted based on $100 \%$ barcode similarity. Sequences were clipped of barcodes and trimmed to a minimum length of $300 \mathrm{nt}$ to best cover the ITS2 part of the nrITS using MOTHUR (Schloss et al. 2009). Sequence reads with an average quality score of $<20$, and homopolymers of $>8$ bases were removed. Unique good quality sequences from the dataset were filtered and checked for chimeras using the uchime algorithm (Edgar et al. 2011) as implemented in MOTHUR. To avoid sampling size effects, the number of reads per sample was normalized for each data set by randomly subsampling to the lower number of reads per samples using the subsample script as implemented in MOTHUR. The sequence dataset was then clustered and assigned to OTUs using CD-HIT-EST of the CD-HIT package version 4.5.4 ( $\mathrm{Li}$ and Godzik 2006) at a $97 \%$ threshold of pairwise sequence similarity as in Wubet et al. (2012). We used MOTHUR to taxonomically assign representative sequences of the OTUs against the UNITE reference database (as downloaded in May 2013) using the default set-up (Abarenkov et al. 2010).

\section{Statistical analysis}

To link WIF richness and taxonomic identity to microbialmediated enzyme activity and decomposition rates, we defined cumulative OTUs (cOTUs) as species synonyms by aggregating OTUs that were unequivocally given the same name by BLAST re-analysis against GenBank yielding at least $95 \%$ (species level) and $90 \%$ (genus level) maximum identity scores (Ovaskainen et al. 2013) for the same database species. The Chao1 and ACE diversity indices were calculated for all OTUs (including 1-3 tons) using the estimate function in the R package "vegan" (Oksanen 2013). All multivariate statistics were conducted on proportional abundance data using the WIF dataset excluding 1-3 tons. Analysis of similarities (ANOSIM) and nonmetric multidimensional scaling (NMDS) based on Bray-Curtis distances were conducted using PAST (Hammer et al. 2001) and the "vegan" package in R (Oksanen 2013), respectively, to compare the fungal community structure of Fagus and Picea. The influence of selected wood physico-chemical parameters, fungal family abundances and environmental factors on fungal community structure was investigated by fitting data on each factor to the NMDS ordinations of the fungal communities. The wood physico-chemical parameters considered in these analyses were decay class, concentrations of macronutrients $(\mathrm{C}, \mathrm{N}, \mathrm{K}$, $\mathrm{Ca}, \mathrm{Mg}, \mathrm{Fe})$ and micronutrients $(\mathrm{Cu}, \mathrm{Mn}, \mathrm{Ni}$ and $\mathrm{Zn})$, relative wood moisture, wood density, remaining mass and $\mathrm{pH}$. Goodness-of-fit statistics $\left(R^{2}\right)$ for environmental variables fitted to the NMDS ordinations of fungal communities were calculated using the envfit function of "vegan", with $P$ values being based on 999 permutations (Oksanen 2013). The $P$ values were Bonferroni-corrected in all cases. We calculated non- parametric Kendall-Tau correlations $(\tau)$ (pairwise comparisons) to link the fungal taxonomic groups to ligninmodifying enzyme activities and decomposition rates using PAST. The differences in OTU richness (observed OTU and cOTU richness and estimated Chaol and ACE richness) and wood physico-chemical properties among different decay classes were analyzed for differences among means $(P<0.05)$ by performing one-way analysis of variance (ANOVA) incorporating Shapiro-Wilk's W test for normality and Levene's test to check for the equality of group variances. Fisher's Least Significant Difference (LSD) post hoc test was also performed.

\section{Results}

\section{Wood physico-chemical properties in different decay classes}

The $\mathrm{C} / \mathrm{N}$ ratios of the deadwood decreased as it decayed, and were significantly higher in Picea logs $(P<0.0001$, ranging from $630 \pm 48.4$ to $423 \pm 52.4)$ than in Fagus logs $(365 \pm 14.9$ to $194 \pm 15.6$ ) (Fig. 1 and Table S3). This difference can be attributed to the significantly higher $\mathrm{C}$ concentrations in Picea deadwood compared to Fagus $(P<0.0001)$, which ranged from $49.3 \% \pm 0.31$ in decay class 1 to $51.4 \% \pm 0.94$ in decay class 4 , and also to the significantly higher $\mathrm{N}$ concentrations in Fagus logs $(P<0.0001)$ compared to Picea. Nitrogen concentrations also increased $(P<0.0001$ for Fagus logs, $P<0.01$ for Picea logs) as wood decay progressed (Fig. 1). The mean total lignin concentrations in Fagus deadwood were lower than in that of Picea (28.9 and $36.0 \%, P<0.0008$ ) and the relative proportion of lignin in the wood increased significantly as it decayed. There were no differences in the mean relative wood moisture, mass loss and decay rate between the two tree species, but these parameters differed significantly between different decay classes within each tree species (Fig. 1). For example, relative wood moisture increased in parallel with decay, from $49.8 \% \pm 5.5$ for decay class 1 to $155.2 \% \pm 9.1$ for decay class 4 in Fagus $(P<0.0001)$ and from $48.7 \% \pm 11.6$ to $163.1 \% \pm 24.6$ in Picea $(P<0.0001)$. The $\mathrm{pH}$ of Fagus 


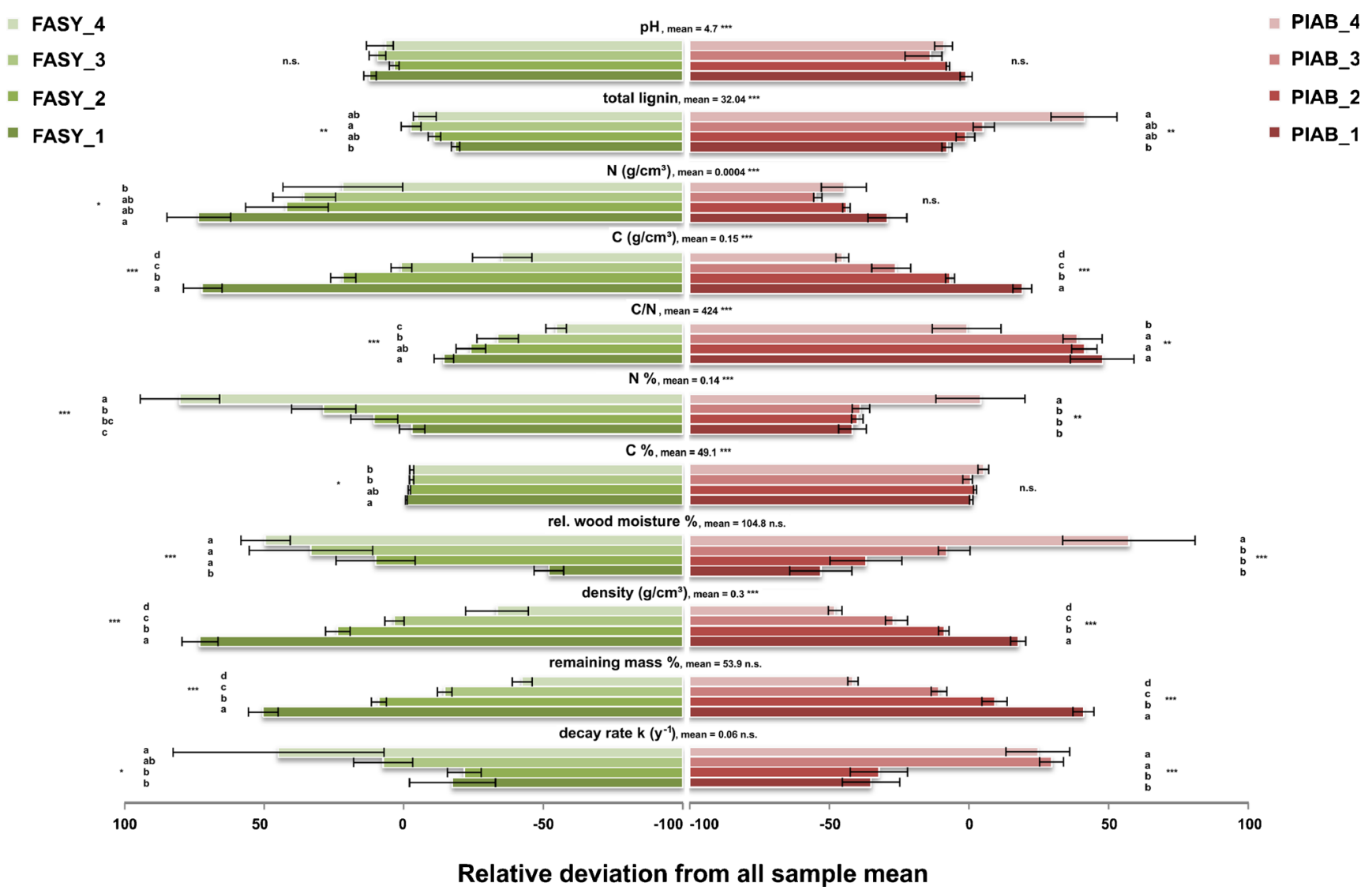

Fig. 1 Decay rates, mass losses, and wood physico-chemical properties of Fagus and Picea deadwood logs of different decay classes. The figure shows the relative deviation from the sample mean in each case. Mean values of all parameters for deadwood logs of both species are shown in the middle. The differences between the two deadwood species and also

deadwood was constant across decay classes and significantly higher than that of Picea deadwood, which declined from 4.6 \pm 0.1 for decay class 1 to $4.3 \pm 0.2$ for decay class 4 . The allocation of micronutrients and the activities of the ligninmodifying enzymes laccases (Lac), manganese peroxidase $(\mathrm{MnP})$ and manganese independent peroxidases (MiP) are provided in supplementary Table S4.

\section{Pyrosequencing and community sampling statistics}

In total, 139,352 reads were obtained from 454 pyrosequencing of 48 deadwood samples. Sequences were initially quality checked, trimmed, normalized per sample and screened for potential chimeras (841 chimeras were removed). CD-HIT clustering of the remaining 86,935 sequences yielded 2,386 OTUs at a $97 \%$ cutoff, of which 1,090 appeared as singletons and 305 as doubletons. Singletons, doubletons, and tripletons were removed from the final dataset, which was considered as having the "rare" taxa excluded. We performed a Mantel test on Bray-Curtis dissimilarities to assess the correlations between the whole matrix and a matrix excluding the rare taxa as just stated. This indicated that the removal of rare taxa from among different decay classes for individual deadwood species were analyzed by t-tests and one-way analysis of variance, incorporated in the form of Fisher's Least Significant Difference (ns=not significant, $* P<0.05, * * P<0.01, * * * P<0.001$ ). The four FASY (Fagus sylvatica) and PIAB (Picea abies) decay classes are shown in different color shades

the community composition had no effect $(R=0.99, P=$ 0.0001 ). In total, 81,803 sequences clustering into 779 OTUs were retained for further statistical analysis after removing sequences that could not be taxonomically assigned to fungi. By applying a species-level sequence divergence threshold of $3 \%$, we were able to taxonomically assign $93.1 \%$ of the filtered OTUs at the phylum level. Basidiomycota accounted for 338 of the filtered OTUs, Ascomycota for 375, and zygomycetes for 9. Chytridiomycota, Entomophthoromycota, and Glomeromycota were represented by 1 OTU each. Further, $614(78.8 \%), 552(70.9 \%)$ and $434(55.7 \%)$ of the filtered OTUs were classified at the order, family and genus levels, respectively. The remaining $6.9 \%$ (54 OTUs) were grouped as unknown fungal OTUs.

\section{Wood-inhabiting fungal richness and community structure}

The total observed fungal OTU richness (excluding rare taxa) per sample ranged from 17 to 102 (25-159 including rare taxa) in logs of Fagus sylvatica and from 28 to 102 (38-151 including rare taxa) in Picea abies logs (Fig. S1). We did not 
observe significant variation in mean OTU richness between the two tree species $(P=0.32)$ (Table S5). All four measures of fungal diversity/ richness (total observed, cumulative, Chaol, and ACE) correlated significantly and positively with decay class, whether it was quantified in terms of declining wood density ( $P<0.05$ Fagus sylvatica, $P<0.001$ on Picea abies) or remaining wood mass (Fig. S2).

While the distribution of OTUs belonging to the Basidiomycota or Ascomycota was comparatively balanced in terms of their presence or absence, their relative abundances differed significantly. For example, the 201 Basidiomycota OTUs identified in Fagus samples contained 25,053 sequences (63.2\% of all sequences) whereas the 265 Ascomycota OTUs (Table S6) only contained 14,091 (35.5\%). There was an even more pronounced pattern in Picea, where the 217 identified Ascomycota OTUs contained only 5,614 (13.3\%) sequences whereas the Basidiomycota accounted for almost $83 \%$ (34, 985) of all sequences clustered into 242 OTUs.

More specifically, 2,487 (6.35\%) sequences were assigned to Annulohypoxylon cohaerens, a common European beech saprotroph of the family Xylariaceae, which also represented the dominant family in the Fagus logs, accounting for 5,377 sequences in total (Figs. 2 and S3). Other important families in the Fagus fungal communities were the Meruliaceae, Polyporaceae, Mycenaceae, Physalacriaceae and Marasmiaceae, that together accounted for $42 \%$ of all identified fungi (Fig. 2). OTUs assigned to the white-rot causing fungus Resinicium bicolor, which is listed as Agaricomycetes I.S. (incertae sedis) in the Index Fungorum (www.indexfungorum.org), were dominant in Picea deadwood,

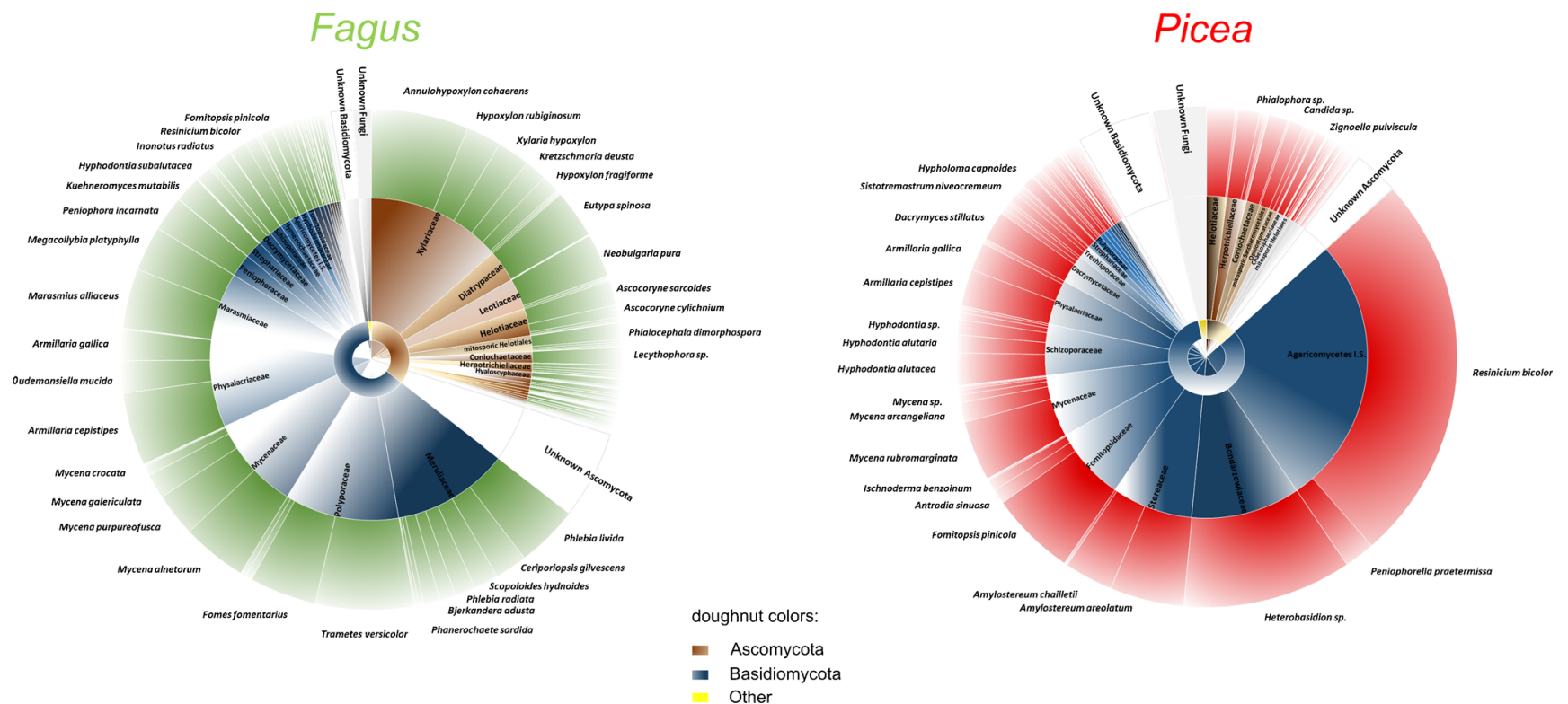

Fig. 2 Patterns of cOTUs on Fagus and Picea deadwood displayed as sunburst charts (beatexcel.com). The outer rings show the cumulative relative abundances of different fungal OTUs (cOTUs) at the species and genus levels with at least 95 and $90 \%$ probability of correct identification, respectively, based on secondary BLAST re-analysis. The accounting for $25.3 \%$ of all sequences. This fungus was detected in $83.3 \%$ of all Picea $\operatorname{logs}$ (Fig. S3). Bondarzewiaceae, represented by Heterobasidion sp., Stereaceae, Fomitopsidaceae and Mycenaceae also occurred frequently and accounted for $32.64 \%$ of the identified sequences/ OTUs. Unidentified species of the Helotiaceae and an OTU identified as the potential soft-rot agent Phialophora $s p$. of the family Herpotrichiellaceae were the most abundant Ascoymcota in Picea but only accounted for 2 and $1.9 \%$ respectively of all identified sequences.

We also examined the sharedness of WIF communities between tree species at species (cOTU) and genus level (Fig. S4ab). Among the 160 cOTUs with the same genus and 2 zygomycetes) were found in both, Picea and Fagus logs (Fig. S4a). Genus-level comparisons revealed that 35 genera were unique to Fagus and, 34 to Picea, while 58 genera were shared (Fig. S4b).

\section{WIF dynamics on deadwood of different tree species}

Different WIF dynamics were clearly observed in the Fagus and Picea logs (Figs. S5, S6). WIF communities in Fagus logs were highly dynamic with respect to wood decay, with no cOTU being dominant in all decay classes. The dominant fungal families and cOTUs in Fagus logs of decay classes 1-4 were Xylariaceae (mainly Annulohypoxylon cohaerens) and Polyporaceae (Trametes versicolor) in decay class 1, Polyporaceae (Fomes fomentarius) and Meruliaceae (Phlebia livida) in decay class 2, Meruliaceae (Ceriporiopsis and species epithets, 74 (22 Ascomycota, 50 Basidiomycota,

middle rings display the cumulative relative abundances at the family level. The inner rings display the cumulative relative abundances of different concordant fungal phyla. Only cOTUs that accounted for $>1 \%$ of the total abundances and identified at least to genus are labeled 
gilvescens), Polyporaceae (Fomes fomentarius) and Marasmiaceae (Megacollybia platyphylla) in decay class 3, and Mycenaceae (Mycena alnetorum), Marasmiaceae (Megacollybia platyphylla, Marasmius alliaceus) and Polyporaceae (Trametes versicolor) in decay class 4. In contrast, all of the Picea decay classes were dominated by a single cOTU assigned to Agaricomycetes I.S. (Resinicium bicolor); the mean abundances of this cOTU in decay classes 1, 2, 3, and 4 were $26.1,36.6,27.6,16.5 \%$, respectively. Some fungal families and cOTUs were also co-dominant in different decay classes: Stereaceae (mainly Amylostereum areolatum) in decay class 1, Fomitopsidaceae (Fomitopsis pinicola) in decay class 3, and Bondarzewiaceae (Heterobasidion sp.) in decay classes 3 and 4 . The WIF dynamics of both deadwood species are described at greater detail in the supporting information.

\section{Factors correlating to fungal community structure in the two deadwood species}

NMDS analysis clearly separated the WIF communities of the two tree species (Fig. 3ab; Table 1). Wood physico-chemical parameters correlated significantly with the fungal community structure (Fig. 3a). Factors that correlated significantly to the variation in the WIF community structure in both tree species were the decay class, relative wood moisture, $\mathrm{pH}$, remaining mass, wood volume, wood density, $\mathrm{C} / \mathrm{N}$ ratio and the concentrations of total lignin, $\mathrm{C}, \mathrm{N}, \mathrm{Mg}, \mathrm{Fe}$ and $\mathrm{Zn}(P=0.024$ $0.0001)$. At the individual tree species level, WIF community structure correlated significantly with decay class, relative wood moisture, remaining mass, wood density and total lignin

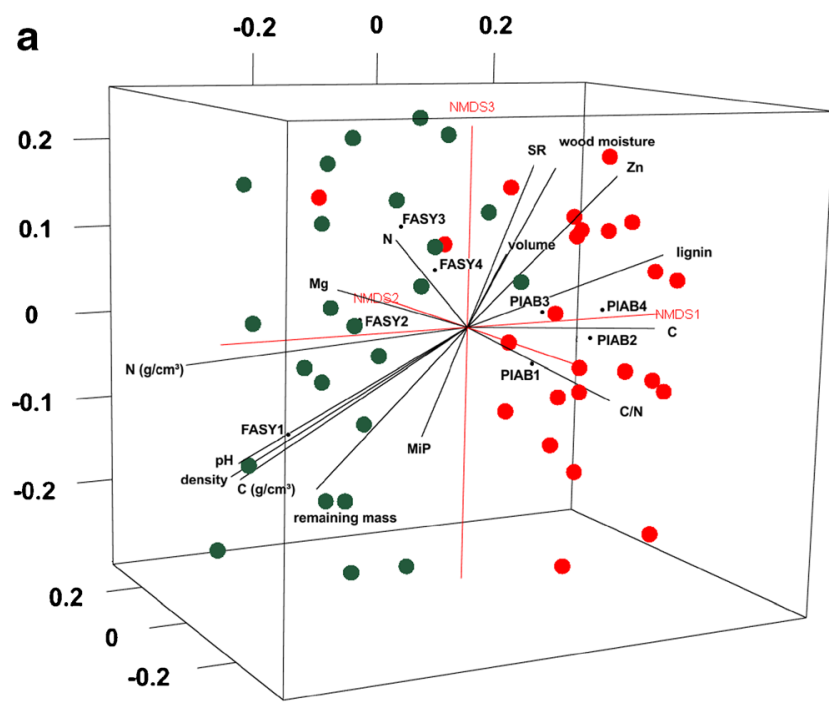

Fig. 3 3D-Nonmetric multidimensional scaling (NMDS) ordination of fungal community structure in Fagus (green) and Picea (red) deadwood using the plot3d and ordigl functions in R. The NMDS ordination (stress $=0.16$ ) was fitted to wood physico-chemical and anthropogenic factors (a) and also abundances of different fungal families (b) by using the envfit command in "vegan". ANOSIM revealed significant separation
(Table 1). In addition, wood volume and $\mathrm{C}$ and $\mathrm{N}$ concentration were important in Fagus deadwood, while the concentrations of total lignin and $\mathrm{Mg}$ were contributing significantly in shaping the fungal community structure in Picea deadwood. Fungal families that correlated significantly with WIF community structure in Fagus and Picea logs are displayed in Fig. 3b.

Relationships between wood-inhabiting fungal richness, taxonomy and lignin-modifying enzyme activities

Correlations between WIF richness (in terms of total observed, cumulative, or estimated OTUs), WIF abundance (at both the family and cOTU levels), and the activities of ligninmodifying enzymes are presented in Table S7. There were no positive correlations between any actual richness of OTU/ cOTU as well as the estimated richness of total OTU and the activities of lignin-modifying enzyme activities. Interestingly, however, there were some significant positive correlations between the abundances of certain fungal families and the measured activity of lignin-modifying enzymes. In Fagus logs, the abundance of the Schizoporaceae and Xylariaceae correlated positively with Lac and MiP activity, respectively $(P<0.05)$. In Picea logs, the abundance of Bondarzewiaceae correlated positively with $\mathrm{MiP}$ and $\mathrm{MnP}$ activity $(P=0.002-0.009)$. We hence found many significant correlations between fungal cOTU abundance and the activity of potential ligninmodifying enzymes (Table S7). In Fagus deadwood, the strongest significant positive correlations were found between Mycena alnetorum and Lac ( $\tau=0.43, P=0.003)$, Hypoxylon rubiginosum and $\mathrm{MiP}(\tau=0.42, P=0.004)$, and Marasmius

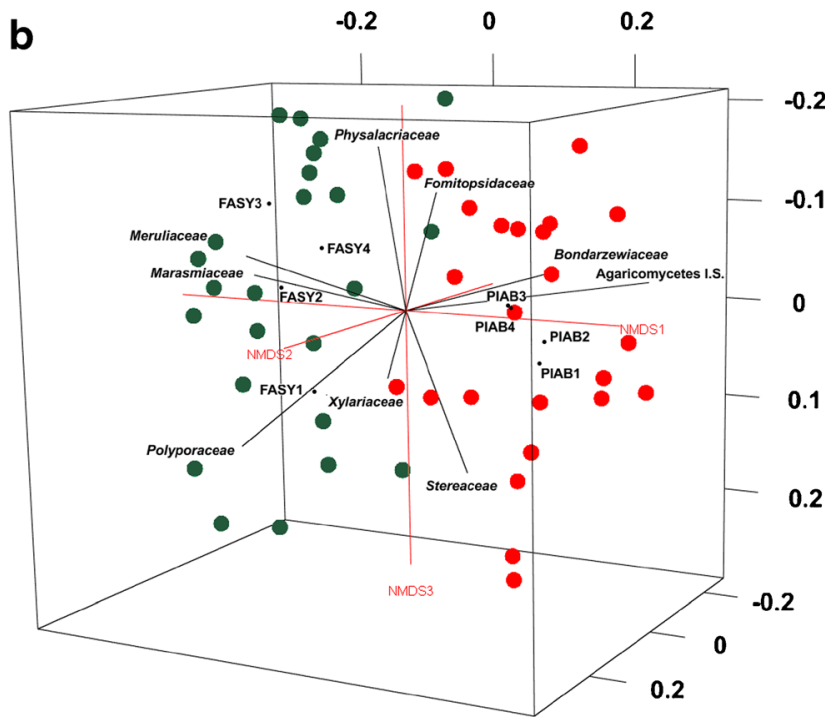

of fungal community structure according to tree species $(R=0.60$, $P<0.001,999$ permutations). To better show the 3-dimensionality of the ordination, two movies in .mp4 format (BB Flashback Express Recorder, Blueberry Software, Birmingham, UK) are available in Suppl. files S1a and S1b 
Table 1 Goodness-of-fit statistics $\left(R^{2}\right)$ for parameters fitted to the nonmetric multidimensional scaling (NMDS) ordination of fungal community structure

\begin{tabular}{|c|c|c|c|c|c|c|}
\hline \multirow[t]{2}{*}{ Parameter } & \multicolumn{2}{|c|}{ Fagus vs Picea } & \multicolumn{2}{|l|}{ Fagus } & \multicolumn{2}{|l|}{ Picea } \\
\hline & $R^{2}$ & $P$ & $R^{2}$ & $P$ & $R^{2}$ & $P$ \\
\hline Fungal OTU richness & 0.1946 & 0.024 & 0.541 & 0.003 & 0.4758 & 0.004 \\
\hline Decay class & 0.4461 & 0.001 & 0.4809 & 0.005 & 0.3634 & 0.022 \\
\hline Remaining mass & 0.497 & 0.001 & 0.546 & 0.003 & 0.3413 & 0.028 \\
\hline Volume & 0.2393 & 0.008 & 0.4975 & 0.004 & 0.1381 & 0.384 \\
\hline Density & 0.6227 & 0.001 & 0.5472 & 0.003 & 0.3098 & 0.047 \\
\hline Relative wood moisture & 0.3094 & 0.002 & 0.5331 & 0.001 & 0.4357 & 0.01 \\
\hline Total lignin & 0.3788 & 0.001 & 0.1847 & 0.256 & 0.7645 & 0.001 \\
\hline $\mathrm{pH}$ & 0.533 & 0.001 & 0.0853 & 0.603 & 0.3384 & 0.039 \\
\hline Decay rate & 0.0728 & 0.378 & 0.2857 & 0.079 & 0.1189 & 0.499 \\
\hline Laccase (Lac) & 0.0502 & 0.527 & 0.1092 & 0.487 & 0.0169 & 0.987 \\
\hline Manganese independent peroxidase (MiP) & 0.1795 & 0.021 & 0.3451 & 0.024 & 0.0852 & 0.679 \\
\hline Manganese peroxidase (MnP) & 0.0729 & 0.328 & 0.0815 & 0.76 & 0.1917 & 0.221 \\
\hline $\mathrm{C} / \mathrm{N}$ & 0.3765 & 0.001 & 0.2555 & 0.119 & 0.0933 & 0.588 \\
\hline $\mathrm{C}$ & 0.2836 & 0.001 & 0.1083 & 0.523 & 0.6272 & 0.001 \\
\hline $\mathrm{N}$ & 0.1941 & 0.024 & 0.2216 & 0.161 & 0.1828 & 0.23 \\
\hline $\mathrm{C}\left(\mathrm{g} / \mathrm{cm}^{3}\right)$ & 0.6 & 0.001 & 0.5435 & 0.003 & 0.2658 & 0.094 \\
\hline $\mathrm{N}\left(\mathrm{g} / \mathrm{cm}^{3}\right)$ & 0.6134 & 0.001 & 0.6111 & 0.002 & 0.1445 & 0.38 \\
\hline $\mathrm{Mn}$ & 0.1507 & 0.057 & 0.0234 & 0.967 & 0.0497 & 0.802 \\
\hline $\mathrm{Mg}$ & 0.3115 & 0.002 & 0.2087 & 0.196 & 0.3407 & 0.027 \\
\hline $\mathrm{Ca}$ & 0.0736 & 0.316 & 0.151 & 0.332 & 0.2589 & 0.112 \\
\hline K & 0.0684 & 0.362 & 0.2733 & 0.099 & 0.2357 & 0.127 \\
\hline $\mathrm{Fe}$ & 0.1876 & 0.016 & 0.1352 & 0.418 & 0.2755 & 0.065 \\
\hline $\mathrm{Cu}$ & 0.1143 & 0.145 & 0.1753 & 0.248 & 0.2928 & 0.061 \\
\hline $\mathrm{Zn}$ & 0.3138 & 0.001 & 0.0863 & 0.613 & 0.0801 & 0.64 \\
\hline $\mathrm{Ni}$ & 0.0718 & 0.366 & 0.153 & 0.357 & 0.1858 & 0.23 \\
\hline
\end{tabular}

The significance estimates were based on 999 permutations. Significant factors (Bonferroni corrected $P<0.05$ ) are indicated in bold. Marginally significant variables (Bonferroni corrected $P<0.10$ ) are indicated in italics alliaceus and $\mathrm{MnP}(\tau=0.31, P=0.036)$. In Picea deadwood, the strongest significant positive correlations were found between Armillaria gallica and Lac $(\tau=0.32, P=0.028)$, Heterobasidion $s p$. and $\operatorname{MiP}(\tau=0.37, P=0.010)$, and Heterobasidion sp. and $\mathrm{MnP}(\tau=0.45, P=0.002)$. In addition, the abundances of certain families and cOTUs exhibited significant negative correlations with lignin-modifying enzyme activity (Table S7).

\section{Relationships between wood-inhabiting fungal richness, taxonomic identity and wood decomposition rates}

There were no significant correlations between total OTU richness (in terms of total observed, cumulative or estimated OTU richness) and wood decomposition rates (Table S8). However, the abundances of specific fungal taxonomic groups and cOTUs correlated significantly with wood decomposition rates. In Fagus deadwood, the abundance of the Xylariaceae family correlated significantly and negatively with decomposition rates $(\tau=-0.44, P=0.003)$. The abundances of three individual species also correlated negatively with decomposition rates: Hypoxylon fragiforme and Xylaria hypoxylon (both Xylariaceae), and Neobulgaria pura (Leotiaceae). On the other hand, Mycena purpureofusca, Phialocephala dimorphospora, Trametes versicolor correlated positively with decomposition rates $(\tau=0.31-0.41, P=0.034-0.005$; Table S8). In Picea deadwood, the abundances of the Schizoporaceae were positively correlated with decomposition rates $(\tau=0.43, P=0.005)$. Individual species whose abundances correlated positively with decomposition rates were Botryobasidium botryosum, Hyphodontia alutacea, Hyphodontia alutaria and Mycena alnetorum ( $\tau=0.32-0.45, P=0.036-0.003$; Table S8).

\section{Discussion}

This work builds on earlier studies that used high-throughput sequencing to investigate fungal community structures in deadwood (Kubartova et al. 2012; Ovaskainen et al. 2013) by providing the first comparison of two morphologically 
different tree species often occurring in close proximity in temperate European forests. By assessing a very comprehensive dataset on physico-chemical wood properties, we were able to identify key factors that correlate with fungal community structure. Moreover, by linking fungal richness and community composition to enzyme activities and decomposition rates, we demonstrated that ecosystem processes are controlled by complex mechanisms such as assembly histories and competition scenarios.

\section{Fungal diversity and community composition}

We found no significant differences between the two deadwood species in terms of total or mean OTU richness. The mean fungal OTU richness tended to increase with increasing decay class. This is inconsistent with the findings of fructification pattern studies, which indicated that the abundance of fruiting bodies was highest at intermediate stages of decay (Heilmann-Clausen 2001; Hoppe et al. 2014). However, the fact that fungal OTU richness increased with losses of mass and density (i.e., as the decay class increased) is in agreement with the results of previous studies on spruce deadwood that used molecular techniques (Kubartova et al. 2012; Rajala et al. 2012). The discrepancy between these findings may be due to the fact that many fungi tend to reside as vegetative mycelia in deadwood and therefore do not develop fruiting bodies (Kubartova et al. 2012).

Only a small proportion of the sequences obtained from deadwood of Picea abies were assignable to Ascomycota, though the ratio of taxonomically assigned OTUs was balanced to Basidiomycota. This result was in line to recent findings on fungal diversity in Norway spruce (Ottosson et al. 2015) and reflects that large parts of biological diversity are only accessible via molecular based techniques (Hibbett et al. 2011)

\section{WIF dynamics during decomposition processes and corresponding factors}

Fungal community structure differed significantly between the two tree species as indicated by the NMDS analysis. The community structure was also more dependent on the species origin of deadwood than on the surrounding forest type. More specifically, fungal communities in Fagus logs in beech stands were more similar to fungal communities in Fagus logs in spruce forests than to fungal communities in Picea deadwood in beech forests. The same was true for Picea logs in spruce and beech stands. This further demonstrates that substrate type has a greater impact on WIF community structure than forest types. Nevertheless, the impact of tree species should be further tested in the future with more tree species, especially those tree species that have similar wood physico-chemical properties. Our results indicate that the physico-chemical properties of the wood (decay class, relative wood moisture, remaining mass, wood density, $\mathrm{C} / \mathrm{N}$ ratio, total lignin) correspond significantly to community structure in both tree species. This is consistent with the report of Rajala et al. (2012) who investigated this aspect in 500 Norway spruce logs.

Deadwood of the two tree species also differed substantially with respect to the way in which their WIF communities changed as the wood decayed. In Picea logs, Resinicium bicolor was dominant in all decay classes; other fungi such as Amylostereum areolatum, Heterobasidion sp. and Fomitopsis pinicola were co-dominant in specific decay classes but much less abundant. Conversely, in Fagus logs, no single fungus was dominant in all decay classes. The dominant species changed from Annulohypoxylon cohaerens and Trametes versicolor in decay class 1 to Fomes fomentarius in decay classes 2 and 3 and then Mycena alnetorum and Trametes versicolor in decay class 4 . It may be surprising that Polyporaceae were still dominant in the decay class 4 since species of this family require substrates with high energy contents to produce fruiting bodies and are therefore consequently rarely found in wood at later stages of the decomposition when using methods that focus on fruiting bodies (Bader et al. 1995; Lindblad 1998). This may be due to the presence of vegetative mycelia and/ or DNA residues in the wood (Kubartova et al. 2012), both of which would be captured by our methodology. However, the change in the dominant polypore species from Fomes fomentarius in decay class 3 to Trametes versicolor in decay class 4 indicates that this phenomenon may not be entirely related to DNA residues.

The fungal community dynamics in Picea deadwood observed in this study were distinctly different compared to those reported for boreal forest ecosystems in Fennoscandia (Kubartova et al. 2012; Ovaskainen et al. 2013; Rajala et al. 2011, 2012). First, the ascomycetes that were reported to be most dominant during the early stages of decay in boreal forests (Rajala et al. 2012) were largely absent in the Central European forests, where basidiomycetes were most abundant across all stages of decay. Secondly, different fungi were dominant at different stages of decay in the boreal environment (Kubartova et al. 2012; Ovaskainen et al. 2013; Rajala et al. 2012), whereas in our study Resinicium bicolor was most abundant in all decay classes. Third, species such as Hyphodontia alutaria, Ascocoryne cylichnium, Heterobasidion parviporum and Fomitopsis pinicola were classified as early colonizers in boreal forests (Kubartova et al. 2012) but were common in all decay classes in our study and even dominant in Picea logs of decay class 4. Finally, ectomycorrhizal (ECM) fungi that were already detected during the early stages of decay in previous studies and became strongly dominant during the final stages of decomposition in boreal forests (Rajala et al. 2012) were largely absent in our study. We did not observe any increase in the abundance of ECM species in the more mineralized wood of decay class 4 . Only 4 ECM cOTUs were detected in a single Picea log in the 
later stages of decay: Lactarius sp. (42 sequences), Laccaria amethystina (22 sequences) Russula fellea (9 sequences) and Xerocomus pruinatus (4 sequences). Together, these species accounted for only $0.18 \%$ of all sequences detected in Picea abies. The relatively low abundance of ECM in Picea logs from temperate forests as compared to boreal forests could be due to differences in N-availability in the two forest ecosystems (Nasholm et al. 1998). We assume that ECM fungi in temperate forests preferentially acquire $\mathrm{N}$ from the soil, whereas in the $\mathrm{N}$-limited boreal environment it is worthwhile for ECM fungi to acquire nitrogen by attacking deadwood (especially highly decayed deadwood) to avoid the competition with forest floor vegetation (Rajala et al. 2011).

\section{The role of WIF in ecosystem functions and processes}

Both the activities of lignin-modifying enzymes and the decomposition rate were related to the abundances of particular fungal families and cumulative OTUs. Laboratory scale studies demonstrated that members of different fungal taxa that were detected in this study (such as Armillaria sp., Fomes fomentarius, Trametes versicolor) can efficiently produce similar amounts of lignin-modifying enzymes (Baldrian 2006) and cause similarly high levels of mass loss (Valmaseda et al. 1990). The co-occurrence of these fungi in deadwood suggests that there is some functional redundancy within the studied WIF communities. Several authors have reported increased Lac and MnP activities due to two-speciesinteractions (Baldrian 2004; Freitag and Morrell 1992; Snajdr et al. 2011; White and Boddy 1992). Chi et al. (2007) found that some combinations of two fungi can accelerate the decay of wood due to increases in $\mathrm{MnP}$ production relative to that observed in equivalent cases featuring only a single fungal species. Whether enzymes are actually secreted due to fungus-fungus interactions or for other reasons may depend on the community structure and the state of degradation of the colonized wood. However, recent studies (Dickie et al. 2012; Dowson et al. 1988a, b; Fukami et al. 2010; Fukasawa et al. 2009) have demonstrated a high degree of interaction among co-existing fungal species, suggesting that WIF may invest more energy into competing with one-another than on producing wood-degrading enzymes under natural field conditions. Coates and Rayner (1985) also found that interaction reduced the rate of wood decay. Therefore, as demonstrated in this work, the high species richness of deadwood-resident fungal communities need not be associated with any increase in the production of wood degrading enzymes or wood decomposition rate. Nevertheless, we identified some fungal OTUs that are known to be active producers of lignin-modifying enzymes and strong wood decomposers that cause a white-rot with high mass loss (Table S9). Trametes versicolor is among the most important decomposers, occurring in all decay classes of Fagus deadwood. We further show that different wood types (deciduous vs. coniferous) directly relate to decomposer (fungal) community structure and dynamics. The decomposition rates on the two deadwood species were not significantly different. This may be due to functional redundancy in their WIF communities and demonstrates that the fungi in each community are adapted to their host tree species. Fungi in coniferous wood have to deal with larger amounts of extractives as well as more recalcitrant and condensed lignin than is encountered in Fagus wood (Blanchette 1991; Higuchi 2006). In respect to anatomy, coniferous woods have simpler structures than deciduous woods (Fengel and Wegener 1983). Such factors will affect fungal substrate preferences. Brown-rot fungi prefer coniferous wood while most white-rot fungi colonize both coniferous and deciduous wood (Hibbett and Donoghue 2001). The preference of brown-rot fungi for coniferous wood was apparent in our data: the three most abundant brown-rot fungi Fomitopsis pinicola, Dacrymyces stillatus and Antrodia sinuosa were found to be much more abundant in Picea than in Fagus. Interestingly, we found more sequences for whiterot fungi in Picea wood than we did for brown-rot fungi. The mean enzyme activities of MiP and MnP in Picea were only marginally lower than those observed for Fagus, further demonstrating the presence of white-rot species in the studied Picea deadwood. These observations are consistent with those of Olsson et al. (2011) and Rajala et al. (2012), who also found white-rot fungi to be more abundant than brown-rot fungi on Picea abies.

The relationships between fungal cOTU richness, family abundances and the activities of lignin-modifying enzymes and decomposition rates were very different in Fagus and Picea logs. The fungal communities in both deadwood species were composed of different cOTUs that were positively correlated and/ or expected to play roles with all lignin-modifying enzyme activities and wood decomposition rates. Interestingly, there were some fungi whose abundances did not correlate positively with lignin-modifying enzyme activity and/ or wood decomposition rates in this field study even though they secreted high titers of lignin-modifying enzymes and caused high mass losses under laboratory conditions. This could be due to the succession of the studied communities (i.e., priority effects) and the interspecific interactions among different fungal species, as discussed above. In addition, ITS is of variable copy number and may not directly correlate to biomass, which could distort the relationship between a fungus's 'abundance' in the dataset and the observed enzymatic activity.

Our results also revealed significantly negative correlations between the abundances of Xylariaceae species and decomposition rates on Fagus logs. Different members of the Xylariaceae were abundant in many Fagus logs of early to intermediate decay classes, and logs harboring these species often exhibited low rates of decomposition. This could be related to the ability of fungi of this family (which cannot produce $\mathrm{MnP}$ ) to impede deadwood colonization by 
secondary saprotrophic basidiomycetes (Fukasawa et al. 2009). Xylariaceae were shown to act very defensively against saprotrophic basidiomycetes on $2 \%$ malt agar and were not displaced by saprotrophic basidiomycetes in twigs over an incubation period of 6 months (Fukasawa et al. 2009). Xylariaceae can form pseudosclerotial plates (PSPs) to delineate decay columns (demarcation lines) within the wood and protect them from attacks by competing saprotrophs. These decay columns can persist even after several years of decomposition (Fukasawa et al. 2009; Purahong and Hyde 2011). We observed similar recalcitrant dense matrices of melanized hyphae (PSPs) in Fagus logs that were highly dominated by Xylariaceae (Fig. S7). Trametes versicolor was also highly abundant in the Fagus deadwood at various stages of decay, and its abundance correlated negatively with that of Xylariaceae members. Interestingly, some logs in the early stages of decay that had been colonized by Trametes versicolor rather than Xylariaceae exhibited very high rates of wood decomposition. This demonstrates the importance of priority effects and interspecific interactions among different fungal species (Hiscox et al. 2015). Trametes versicolor has been shown to secrete large quantities of different ligninmodifying enzymes and yields high wood decomposition rates under laboratory condition (Valmaseda et al. 1990). We assume that the properties and species origin of deadwood affects both the dynamics of the fungal community and the interactions among different fungal species. Many fungal OTUs were present in both Fagus and Picea deadwood but the dominance patterns and temporal dynamics of the communities in each case differed substantially (Figs. S3, S4).

\section{Conclusion}

Fungal community structure was significantly different between deadwood of Fagus sylvatica and Picea abies occurring in close proximity in temperate forests of Germany. Wood physico-chemical properties are the main factors corresponding to the fungal communities in these deadwood species. Under the studied natural conditions, microbial-mediated ecosystem functions (i.e., the activities of lignin-modifying enzymes) and processes (wood decomposition rate) were controlled by successional assembly history, interspecific interactions and competition scenarios rather than total OTU/-species richness (Dickie et al. 2012; Fukami et al. 2010; Hiscox et al. 2015).

\footnotetext{
Acknowledgments Our work was funded in part by contributing projects to the DFG Priority Program 1374 on "Infrastructure-BiodiversityExploratories" (KR 3587/1-1, KR 3587/3-2, BA 2821/9-2, BU 941/17-1, HO 1961/5-1, HO 1961/5-2). We thank the managers of the three Exploratories, Swen Renner, Sonja Gockel, Kerstin Wiesner and Martin Gorke for their work in maintaining the plot and project infrastructure; Simone Pfeiffer and Christiane Fischer giving support through the central office, Michael Owonibi for managing the central data base, and Markus Fischer,
}

Eduard Linsenmair, Dominik Hessenmöller, Jens Nieschulze, Daniel Prati, Ingo Schöning, Ernst-Detlef Schulze, Wolfgang W. Weisser and the late Elisabeth Kalko for their role in setting up the Biodiversity Exploratories project. Field work permits were issued by the responsible state environmental offices of Baden-Württemberg (according to $\S 72$ $\mathrm{BbgNatSchG).} \mathrm{The} \mathrm{funders} \mathrm{had} \mathrm{no} \mathrm{role} \mathrm{in} \mathrm{the} \mathrm{study} \mathrm{design,} \mathrm{data} \mathrm{collec-}$ tion and analysis, decision to publish, or the preparation of the manuscript. Julia Moll, Harald Kellner and Renate Rudloff are thanked for helpful comments or laboratory support. Sigrid Härtling and Beatrix Schnabel performed the 454 sequencing at the Department of Soil Ecology. Kezia Goldmann and Guillaume Lentendu helped with bioinformatics. Andrea Gargas helped in language editing.

Data accessibility The raw sequence data are available from the NCBI Sequence Read Archive (http://www.ncbi.nlm.nih.gov/Traces/study/) under experiment SRX589508. Corresponding MIDs and metadata are provided in Table $\mathrm{S} 2$.

Open Access This article is distributed under the terms of the Creative Commons Attribution 4.0 International License (http:// creativecommons.org/licenses/by/4.0/), which permits unrestricted use, distribution, and reproduction in any medium, provided you give appropriate credit to the original author(s) and the source, provide a link to the Creative Commons license, and indicate if changes were made.

\section{References}

Abarenkov K, Henrik Nilsson R, Larsson K-H et al (2010) The UNITE database for molecular identification of fungi - recent updates and future perspectives. New Phytol 186:281-285

Bader P, Jansson S, Jonsson BG (1995) Wood-inhabiting fungi and substratum decline in selectively logged boreal spruce forests. Biol Conserv 72:355-362

Baldrian P (2004) Increase of laccase activity during interspecific interactions of white-rot fungi. FEMS Microbiol Ecol 50:245-253

Baldrian P (2006) Fungal laccases - occurrence and properties. FEMS Microbiol Rev 30:215-242

Blanchette RA (1991) Delignification by wood-decay fungi. Annu Rev Phytopathol 29:381-398

Blaser S, Prati D, Senn-Irlet B, Fischer M (2013) Effects of forest management on the diversity of deadwood-inhabiting fungi in Central European forests. For Ecol Manag 304:42-48

Boddy L (2001) Fungal community ecology and wood decomposition processes in angiosperms: from standing tree to complete decay of coarse woody debris. Ecol Bull 49:43-56

Chi YJ, Hatakka A, Maijala P (2007) Can co-culturing of two white-rot fungi increase lignin degradation and the production of lignindegrading enzymes? Int Biodeterior Biodegrad 59:32-39

Coates D, Rayner ADM (1985) Fungal population and communitydevelopment in cut beech logs. 3. Spatial dynamics, interactions and strategies. New Phytol 101:183-198

Coleman DC, Whitman WB (2005) Linking species richness, biodiversity and ecosystem function in soil systems. Pedobiologia 49: 479-497

Dickie IA, Fukami T, Wilkie JP, Allen RB, Buchanan PK (2012) Do assembly history effects attenuate from species to ecosystem properties? A field test with wood-inhabiting fungi. Ecol Lett $15: 133-141$

Dowson CG, Rayner ADM, Boddy L (1988a) Inoculation of mycelial cord-forming basidiomycetes into woodland soil and litter. 1. Initial establishment. New Phytol 109:335-341 
Dowson CG, Rayner ADM, Boddy L (1988b) Inoculation of mycelial cord-forming basidiomycetes into woodland soil and litter. 2. Resource capture and persistence. New Phytol 109:343-349

Doyle JJ, Doyle JL (1987) A rapid DNA isolation procedure for small quantities of fresh leaf tissue. Phytochem Bull 19:11-15

Edgar RC, Haas BJ, Clemente JC, Quince C, Knight R (2011) UCHIME improves sensitivity and speed of chimera detection. Bioinformatics 27:2194-2200

Effland MJ (1977) Modified procedure to determine acid-insoluble lignin in wood and pulp. Tappi 60:143-144

Eisenhauer N, Scheu S, Jousset A (2012) Bacterial diversity stabilizes community productivity. PLoS ONE e34517. doi: 10.1371/journal. pone. 0034517

Fengel D, Wegener G (1983) Wood: Chemistry, Ultrastructure, Reactions. Walter de Gruyter, Berlin and New York

Fischer M, Bossdorf O, Gockel S et al (2010) Implementing large-scale and long-term functional biodiversity research: the biodiversity exploratories. Basic Appl Ecol 11:473-485

Floudas D, Binder M, Riley R et al (2012) The paleozoic origin of enzymatic lignin decomposition reconstructed from 31 fungal genomes. Science 336:1715-1719

Freitag M, Morrell JJ (1992) Changes in selected enzyme-activities during growth of pure and mixed cultures of the white-rot decay fungus Trametes versicolor and the potential biocontrol fungus Trichoderma harzianum. Can J Microbiol 38:317-323

Fukami T, Dickie IA, Wilkie JP et al (2010) Assembly history dictates ecosystem functioning: evidence from wood decomposer communities. Ecol Lett 13:675-684

Fukasawa Y, Osono T, Takeda H (2009) Effects of attack of saprobic fungi on twig litter decomposition by endophytic fungi. Ecol Res 24:1067-1073

Gadd GM (2010) Metals, minerals and microbes: geomicrobiology and bioremediation. Microbiology 156:609-643

Gardes M, Bruns TD (1993) ITS primers with enhanced specificity for basidiomycetes - application to the identification of mycorrhizae and rusts. Mol Ecol 2:113-118

Hahn F, Ullrich R, Hofrichter M, Liers C (2013) Experimental approach to follow the spatiotemporal wood degradation in fungal microcosms. Biotechnol J 8:127-132

Halme P, Kotiaho JS (2012) The importance of timing and number of surveys in fungal biodiversity research. Biodivers Conserv 21: 205-219

Hammer Ø, Harper DAT, Ryan PD (2001) PAST: paleontological statistics software package for education and data analysis. Palaeontol Electron 4:1-9

Harmon ME, Franklin JF, Swanson FJ et al (1986) Ecology of coarse woody debris in temperate ecosystems. Adv Ecol Res 15:133-302

Hatakka A, Hammel K (2011) Fungal biodegradation of lignocelluloses. In: Hofrichter M (ed) The Mycota: a comprehensive treatise on fungi as experimental systems for basic and applied research. Industrial applications. Springer, Heidelberg, pp 319-340

Heilmann-Clausen J (2001) A gradient analysis of communities of macrofungi and slime moulds on decaying beech logs. Mycol Res 105:575-596

Heilmann-Clausen J, Christensen M (2003) Fungal diversity on decaying beech logs - implications for sustainable forestry. Biodivers Conserv 12:953-973

Hessenmöller D, Nieschulze J, Seele C, von Lüpke N, Schulze ED (2011) Identification of forest management types from ground-based and remotely sensed variables and the effects of forest management on forest structure and composition. Forstarchiv 82:171-183

Hibbett DS, Donoghue MJ (2001) Analysis of character correlations among wood decay mechanisms, mating systems, and substrate ranges in homobasidiomycetes. Syst Biol 50:215-242

Hibbett DS, Ohman A, Glotzer D, Nuhn M, Kirk P, Nilsson RH (2011) Progress in molecular and morphological taxon discovery in Fungi and options for formal classification of environmental sequences. Fungal Biol Rev 25:38-47

Higuchi T (2006) Look back over the studies of lignin biochemistry. J Wood Sci 52:2-8

Hiscox J, Savoury M, Müller CT, Lindahl B, Rogers HJ, Boddy L (2015) Priority effects during fungal community establishment in beech wood. ISME J. doi:10.1038/ismej.2015.38

Hofrichter M, Ullrich R, Pecyna MJ, Liers C, Lundell T (2010) New and classic families of secreted fungal heme peroxidases. Appl Microbiol Biotechnol 87:871-897

Hoppe B, Kahl T, Karasch P, Wubet T, Bauhus J, Buscot F, Krüger D (2014) Network analysis reveals ecological links between N-fixing bacteria and wood-decaying fungi. PLoS ONE e88141. doi:10. 1371/journal.pone.0088141

Hoppe B, Krüger D, Kahl T, Arnstadt T, Buscot F, Bauhus F, Wubet T (2015) A pyrosequencing insight into sprawling bacterial diversity and community dynamics in decaying deadwood logs of Fagus sylvatica and Picea abies. Sci Rep. doi:10.1038/srep09456

Jellison J, Connolly J, Goodell B et al (1997) The role of cations in the biodegradation of wood by the brown rot fungi. Int Biodeterior Biodegrad 39:165-179

Kahl T, Mund M, Bauhus J, Schulze ED (2012) Dissolved organic carbon from European beech logs: patterns of input to and retention by surface soil. Ecoscience 19:1-10

Kögel-Knabner I (2002) The macromolecular organic composition of plant and microbial residues as inputs to soil organic matter. Soil Biol Biochem 34:139-162

Kopra K, Fyles J (2005) Woody debris and nutrient cycling: should we care??? SFMN Res Note Ser 8

Krankina ON, Harmon ME, Griazkin AV (1999) Nutrient stores and dynamics of woody detritus in a boreal forest: modeling potential implications at the stand level. Can J For Res 29:20-32

Kubartova A, Ottosson E, Dahlberg A, Stenlid J (2012) Patterns of fungal communities among and within decaying logs, revealed by 454 sequencing. Mol Ecol 21:4514-4532

Lentendu G, Wubet T, Chatzinotas A, Wilhelm C, Buscot F, Schlegel M (2014) Effects of long term differential fertilization on eukaryotic microbial communities in an arable soil: a multiple barcoding approach. Mol Ecol 23:3341-3355

Li W, Godzik A (2006) Cd-hit: a fast program for clustering and comparing large sets of protein or nucleotide sequences. Bioinformatics 22: $1658-1659$

Liers C, Arnstadt T, Ullrich R, Hofrichter M (2011) Patterns of lignin degradation and oxidative enzyme secretion by different wood- and litter-colonizing basidiomycetes and ascomycetes grown on beechwood. FEMS Microbiol Ecol 78:91-102

Lindblad I (1998) Wood-inhabiting fungi on fallen logs of Norway spruce: relations to forest management and substrate quality. Nord J Bot 18:243-255

Luyssaert S, Hessenmoller D, von Lupke N, Kaiser S, Schulze ED (2011) Quantifying land use and disturbance intensity in forestry, based on the self-thinning relationship. Ecol Appl 21:3272-3284

Martinez AT, Speranza M, Ruiz-Duenas FJ et al (2005) Biodegradation of lignocellulosics: microbial chemical, and enzymatic aspects of the fungal attack of lignin. Int Microbiol 8:195-204

Müller J, Engel H, Blaschke M (2007) Assemblages of wood-inhabiting fungi related to silvicultural management intensity in beech forests in southern Germany. Eur J For Res 126:513-527

Nasholm T, Ekblad A, Nordin A et al (1998) Boreal forest plants take up organic nitrogen. Nature 392:914-916

Oksanen J (2013) Multivariate analysis of ecological communities in R: vegan tutorial. $<$ http://cc.oulu.fi/ jarioksa/opetus/metodi/ vegantutor.pdf $>$ (accessed: August 20th 2014)

Olsson J, Jonsson BG, Hjalten J, Ericson L (2011) Addition of coarse woody debris - the early fungal succession on Picea abies logs in managed forests and reserves. Biol Conserv 144:1100-1110 
Ottosson E, Kubartova A, Edmann M, Jönsson M, Lindhe A, Stenlid J, Dahlberg A (2015) Diverse ecological roles within fungal communities in decomposing logs of Picea abies. FEMS Microbiol Ecol. doi:10.1093/femsec/fiv012

Ovaskainen O, Nokso-Koivista J, Hottola J et al (2010) Identifying woodinhabiting fungi with 454 sequencing - what is the probability that BLAST gives the correct species? Fungal Ecol 3:274-283

Ovaskainen O, Schigel D, Ali-Kovero H et al (2013) Combining highthroughput sequencing with fruit body surveys reveals contrasting life-history strategies in fungi. ISME J 7:1696-1709

Pollierer MM, Dyckmans J, Scheu S, Haubert D (2012) Carbon flux through fungi and bacteria into the forest soil animal food as indicated by compound- specific ${ }^{13} \mathrm{C}$ fatty acid analysis. Funct Ecol 26 : 978-990

Proulx R, Wirth C, Voigt W, et al (2010) Diversity promotes temporal stability across levels of ecosystem organization in experimental grasslands. PLoS ONE e13382. doi:10.1371/journal.pone.0013382

Purahong W, Hyde KD (2011) Effects of fungal endophytes on grass and non-grass litter decomposition rates. Fungal Divers 47:1-7

Purahong W, Hoppe B, Kahl T et al (2014a) Changes within a single landuse category alter microbial diversity and community structure: molecular evidence from wood-inhabiting fungi in forest ecosystems. J Environ Manag 139:109-119

Purahong W, Kahl T, Schloter M et al (2014b) Comparing fungal richness and community composition in coarse woody debris in Central European beech forests under three types of management. Mycol Prog. doi:10.1007/s11557-013-0954-y

Raiskila S, Pulkkinen M, Laakso T et al (2007) FTIR spectroscopic prediction of mason and acid soluble lignin variation in Norway spruce cutting clones. Silva Fennica 41:351-371

Rajala T, Peltoniemi M, Pennanen T, Makipää R (2010) Relationship between wood-inhabiting fungi determined by molecular analysis (denaturing gradient gel electrophoresis) and quality of decaying logs. Can J For Res 40:2384-2397

Rajala T, Peltoniemi M, Hantula J, Makipää R, Pennanen T (2011) RNA reveals a succession of active fungi during the decay of Norway spruce logs. Fungal Ecol 4:437-448

Rajala T, Peltoniemi M, Pennanen T, Makipää R (2012) Fungal community dynamics in relation to substrate quality of decaying Norway spruce (Picea abies L. Karst.) logs in boreal forests. FEMS Microbiol Ecol 81:494-505
Sarkanen KV, Ludwig CH (1971) Lignins: Occurrence, Formation, Structure and Reactions. Wiley, New York

Schloss PD, Westcott SL, Ryabin T et al (2009) Introducing mothur: open-source, platform-independent, community-supported software for describing and comparing microbial communities. Appl Environ Microbiol 75:7537-7541

Schwarze F, Engels J, Mattheck C (2000) Fungal Strategies of Wood Decay in Trees. Springer, Berlin

Snajdr J, Dobiasova P, Vetrovsky T et al (2011) Saprotrophic basidiomycete mycelia and their interspecific interactions affect the spatial distribution of extracellular enzymes in soil. FEMS Microbiol Ecol 78:80-90

Stokland JN, Siitonen J, Jonsson BG (2012) Biodiversity in Dead Wood. Cambridge University Press, Cambridge

Valmaseda M, Almendros G, Martinez AT (1990) Substratedependent degradation patterns in the decay of wheat straw and beech wood by ligninolytic fungi. Appl Microbiol Biotechnol 33:481-484

Valentin L, Rajala T, Peltoniemi M et al (2014) Loss of diversity in woodinhabiting fungal communities affects decomposition activity in Norway spruce wood. Front Microbiol 5:230

van der Heijden MGA, Klironomos JN, Ursic M et al (1998) Mycorrhizal fungal diversity determines plant biodiversity, ecosystem variability and productivity. Nature 396:72-75

van der Wal A, Ottosson E, de Boer W (2015) Neglected role of fungal community composition in explaining variation in wood decay rates. Ecology 96:124-133

White NA, Boddy L (1992) Extracellular enzyme localization during interspecific fungal interactions. FEMS Microbiol Lett 98:75-79

White T, Bruns T, Lee S, Taylor J (1990) Amplification and direct sequencing of fungal ribosomal RNA genes for phylogenetics. In: Innis MA, Gelfand DH, Sninsky JJ, White TJ (eds) PCR Protocols: A Guide to Methods and Applications. Academic, San Diego and Heidelberg, pp 315-322

Wubet T, Christ S, Schöning I, Boch S, Gawlich M, Schnabel B, Fischer M, Buscot F (2012) Differences in soil fungal communities between European beech (Fagus sylvatica $\mathrm{L}$.) dominated forests are related to soil and understory vegetation. PLoS ONE 7(10): e47500. doi:10. 1371/journal.pone. 0047500 